\title{
Potencial de uso agrícola e nutricional de cultivares crioulas de feijão
}

\author{
Cropping and nutritional potential of common bean land varieties
}

\author{
Nerinéia Dalfollo Ribeiro ${ }^{\mathrm{I}}$ Irajá Ferreira Antunes $^{\mathrm{II}}$ Nerison Luiz Poersch ${ }^{\mathrm{III}}$ \\ Simone Saydelles da Rosa ${ }^{\text {III }}$ Marcelo Grandi Teixeira ${ }^{\text {IV }}$
}

Ana Lúcia da Silva Gomes ${ }^{\text {III }}$

\section{RESUMO}

O valor nutricional e o potencial de uso agrícola de cultivares crioulas de feijão não têm sido suficientemente avaliados, sendo este o objetivo deste trabalho. O experimento foi conduzido nos anos agrícolas 2004/05 e 2005/06, em Santa Maria, RS, no delineamento experimental de látice triplo $6 \times 6$. Os tratamentos consistiram de 32 cultivares crioulas de feijão e quatro cultivares desenvolvidas pela pesquisa. Interação cultivar x ano foi observada em relação ao rendimento de grãos, à coloração do tegumento dos grãos e ao ciclo, evidenciando resposta diferenciada das cultivares crioulas aos anos de avaliação. Foi possível a identificação de cultivares crioulas com elevado potencial de rendimento de grãos, com coloração de tegumento de grãos adequada para os diferentes grupos comerciais, com precocidade e teor elevado de fibra alimentar. Nesse sentido, as cultivares crioulas - "21 INT-ps 1”, “9 BR-ps 5”, “9 BR-ps 15”, “9 BR-ps 13”, “9 BR-ps 7”, "38 MO M-ps 11 ” e “36 BR MP-ps 14” - são promissoras para uso em programas de melhoramento genético devido ao elevado potencial de uso agrícola. A cultivar crioula "24 OPps 1 " apresentou o maior teor de fibra alimentar e o seu potencial de uso como alimento funcional deve ser investigado.

Palavras-chave: Phaseolus vulgaris L., variabilidade genética, seleção, fibra alimentar.

\section{ABSTRACT}

The objective of this study was to evaluate the nutrition and the crop values of common bean land varieties. The experiments were conducted in Santa Maria, RS, Brazil, in 2004/05 and 2005/06 cropping years, in a $6 \times 6$ triple lattice design. Treatments were composed of 32 common bean land varieties and four research-derived cultivars. Cultivar $x$ environment interaction was detected for grain yield, seed coat color and cycle, what reveals a differential response of the

\begin{abstract}
land varieties to the different crop years. Land varieties were identified with high grain yield potential, commercially acceptable seed coat color from different commercial groups, early maturity and high dietary fiber content. '21 INT-ps 1', '9 BR-ps 5', '9 BR-ps 15', '9 BR-ps 13', '9 BR-ps 7', '38 MO Mps 11 ' and '36 BR MP-ps 14' - are promising land varieties for use in breeding programs due to their high agricultural potential. Cultivar '24 OP-ps 1' presented high dietary fiber content and its potential as functional food needs further studies.
\end{abstract}

Key words: Phaseolus vulgaris L., genetic variability, selection, dietary fiber.

\section{INTRODUÇÃO}

O feijão (Phaseolus vulgaris L.) foi introduzido no Brasil, provavelmente, por duas rotas distintas: pela América Central - grãos pequenos - e pelos Andes - grãos grandes (McCLEAN et al., 1993). É uma espécie que revela multiplicação, predominantemente, por autofecundação, mas baixa percentagem de fecundação cruzada (1 a 3\%) pode ser verificada, propiciando o surgimento de muitas variantes com o passar dos anos. Além disso, o feijão é cultivado numa grande diversidade de ambientes, o que contribui para a ocorrência de variabilidade. Como conseqüência, a biodiversidade obtida adquire uma importância incalculável para a humanidade. Nesse sentido, é importante a avaliação do potencial de uso agrícola e nutricional das cultivares crioulas de feijão fonte de variabilidade obtida pela seleção natural ou

\footnotetext{
IDepartamento de Fitotecnia, Centro de Ciências Rurais (CCR), Universidade Federal de Santa Maria (UFSM), 97105-900, Santa Maria, RS, Brasil. E-mail: neiadr@smail.ufsm.br. Autor para correspondência.

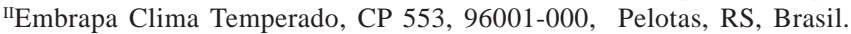

${ }^{\text {IIIC }}$ urso de Agronomia, CCR, UFSM, Santa Maria, RS, Brasil.

${ }^{\mathrm{IV}}$ Embrapa Agrobiologia, Seropédica, RJ, Brasil.
} 
humana. Isso porque as cultivares crioulas - conhecidas como land varieties - constituem a base da sustentabilidade da agricultura familiar na Região Sul do país. O reconhecimento desse potencial tem sido explorado na composição de populações de base genética ampla, destinadas à seleção de linhas promissoras sob ambientes diversos (ANTUNES et al., 1991).

O feijão é fonte de proteínas, carboidratos complexos, fibra e nutrientes essenciais à dieta, além de possuir baixo teor de gordura e sódio e não conter colesterol (GEIL \& ANDERSON, 1994). De acordo com esses autores, o consumo de feijão proporciona efeitos preventivos e terapêuticos para doenças do coração, diabetes, obesidade e câncer, sendo então extensivamente estudado, e inúmeros benefícios à saúde são associados ao aumento da ingestão de fibras.

Além disso, quando comparado aos cereais (trigo, arroz e milho) e a várias hortaliças, o feijão é o alimento de origem vegetal que apresenta maior teor de fibra alimentar (ACEVEDO \& BRESSANI, 1990). A fibra alimentar é composta pela fração solúvel substâncias pécticas, gomas, algumas hemiceluloses e $\beta$-glucanas, e pela fração insolúvel - celulose, lignina e a maioria das hemiceluloses (GUERRA et al., 2004).

As frações que compõem a fibra alimentar exercem efeitos fisiológicos importantes no organismo. As fibras solúveis têm a propriedade de reduzir a absorção de glicose e do colesterol plasmático, enquanto que as fibras insolúveis aceleram o tempo de trânsito intestinal, auxiliando na prevenção de doenças do trato gastrointestinal (OLSON et al., 1987; MOORE et al., 1998; VANDERHOOF, 1998). O feijão é um dos poucos alimentos que possui conteúdo balanceado de fibras solúvel e insolúvel (HUGHES, 1991), por isso pode e deve compor os cardápios. Adicionalmente, o feijão constitui a base alimentar da maioria dos brasileiros, sobretudo nas classes sociais de baixa renda, devido ao menor custo quando comparado, por exemplo, às fontes de proteínas de origem animal.

A determinação da composição de fibra presente nos grãos é essencial para a utilização das cultivares de feijão na composição de dietas alimentares diferenciadas. Isso porque grãos de feijão de diferentes grupos comerciais apresentam variação no teor de fibra alimentar e de suas frações. Assim, ACEVEDO \& BRESSANI (1990) observaram maior teor de fibra alimentar (FA) em feijão preto (26,77\%), sendo que a percentagem de fibra insolúvel (FI) foi de 22,64\% e a de fibra solúvel (FS), de 4,13\%. Já, em grãos de feijão roxo, valores de $25,95 \%$ de FA, $22,87 \%$ de FI e 3,08\% de FS foram constatados. Os grãos de feijão branco apresentaram os menores valores de FA(24,65\%), com fração insolúvel de 20,51\% e solúvel de 4,14\%. Também é importante considerar que presença de interação genótipo $\mathrm{x}$ ambiente foi observada para fibra alimentar quando se avaliaram cultivares de feijão em dois municípios do Estado do Rio Grande do Sul (LONDERO et al., 2006b).

A fibra alimentar variou de 33,39\% a 39,39\% em grãos de feijão de cultivares brasileiras e nas populações obtidas a partir dos cruzamentos possíveis entre “CNFP 8100”, “FT 96-1282”, "BRS Valente” e "Varre-Sai” (LONDERO et al., 2005). A FI variou de $24,82 \%$ a $31,35 \%$ e a FS foi de $8,04 \%$ a $11,11 \%$ nos parentais e nas populações segregantes obtidas (LONDERO et al., 2006a). Além disso, alta herdabilidade no sentido amplo $(97,03 \%)$ e alto ganho por seleção predito $(5,36 \%)$ foram constatados no cruzamento entre "BRS Valente” x "Varre-Sai”. Sendo assim, os autores sugerem que a seleção de plantas $F_{2}$ em populações segregantes desenvolvidas a partir desse cruzamento poderá ser efetiva no desenvolvimento de germoplasma de feijão com maior teor de fibra alimentar.

Considerando que existe variabilidade genética para a fibra alimentar e para as diferentes frações, é esperado que a seleção seja eficiente e que cultivares de feijão com melhor qualidade nutricional possam ser obtidas nos programas de melhoramento. Assim, dietas poderão ser formuladas para atender às mais variadas necessidades alimentares.

Sendo assim, o objetivo deste trabalho foi avaliar o valor agronômico e o teor de fibra alimentar em cultivares crioulas de feijão, com vistas ao uso direto como cultivares, ou em programas de melhoramento.

\section{MATERIALEMETÓDOS}

Os experimentos foram conduzidos nos anos agrícolas de 2004/05 e de 2005/06, em área do Departamento de Fitotecnia da Universidade Federal de Santa Maria (UFSM), Santa Maria, Rio Grande do Sul, Brasil. Os cultivos foram realizados em época de safra, com semeadura em 28/10/2004 e em 26/10/2005, também denominado de cultivo das águas, em área localizada a 95m de altitude, latitude $29^{\circ} 42$ 'S e longitude $53^{\circ} 49^{\prime} \mathrm{W}$.

O delineamento experimental utilizado foi o látice triplo 6 x 6 . Os tratamentos consistiram de 32 seleções realizadas em cultivares crioulas de feijão e em quatro cultivares desenvolvidas pela pesquisa - "BRS Campeiro”, “BRS Expedito”, “Iraí” " “Iapar 31” (Tabela 1). O germoplasma original utilizado foi coletado pela Embrapa-Clima Temperado em propriedades agrícolas de pequeno porte na Região Sul do país. As parcelas 
Tabela 1 - Coloração do grão (cor do grão), coloração das inflorescências (cor de flor), hábito de crescimento (HC) e massa de 100 sementes (massa, g) de cultivares crioulas de feijão avaliadas em dois anos agrícolas.

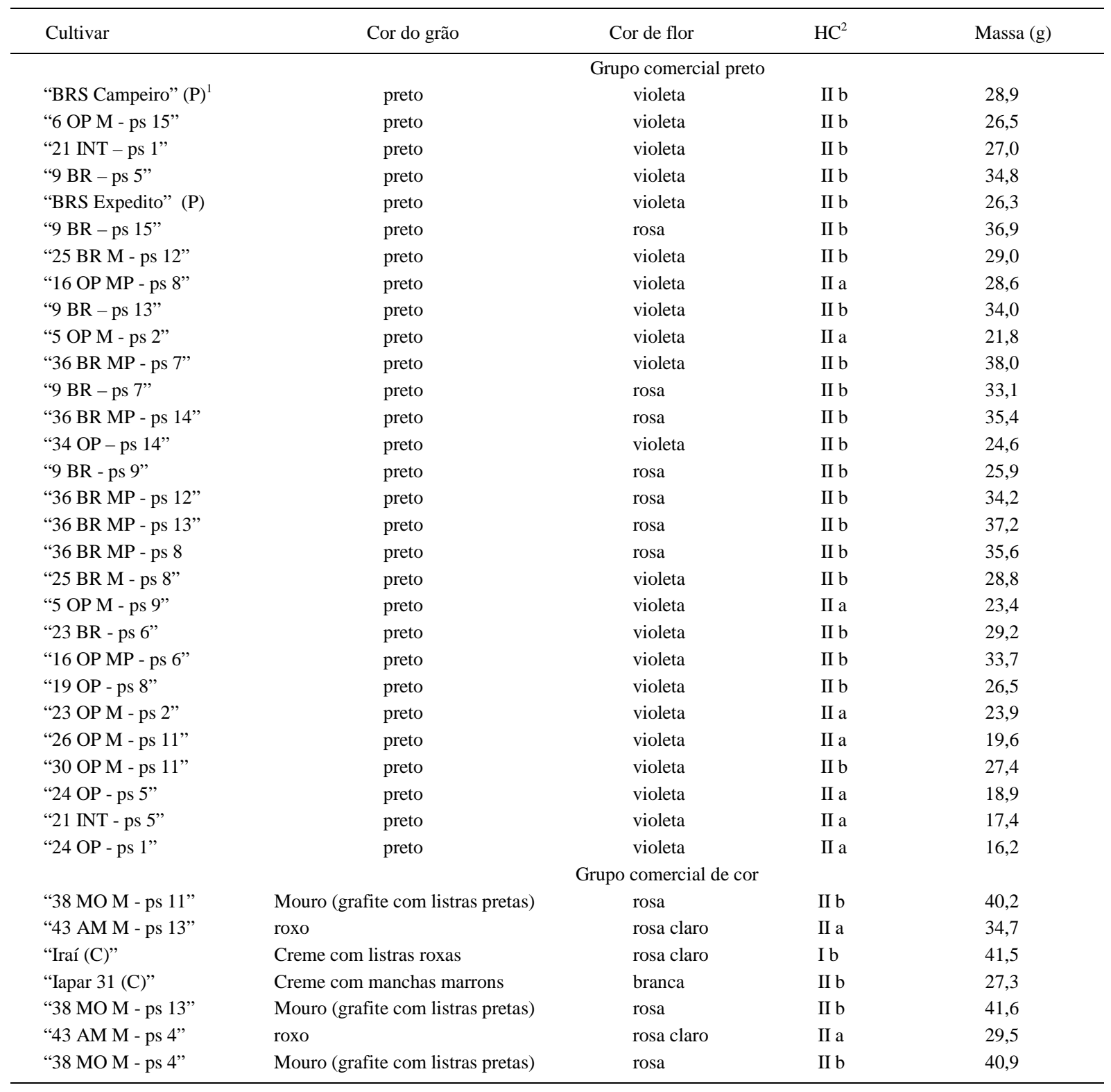

${ }^{\mathrm{I}}$ Letras seguindo a identificação do genótipo representam: (P): cultivar testemunha de grãos pretos; (C): cultivar testemunha de grãos de cor. ${ }^{\mathrm{II}} \mathrm{HC}=$ hábito de crescimento: Ib: determinado, com ramificações eretas e fechadas, com maior número de internódios e de tamanho mais longo, por isso tendem a acamar; II: indeterminado, com guias curtas, possuindo mais de 12 nós na haste principal; (IIa) plantas eretas e arbustivas; (IIb) plantas semitrepadoras.

foram compostas de duas fileiras de $4 \mathrm{~m}$ de comprimento, espaçadas de $0,50 \mathrm{~m}$, e área útil de $3 \mathrm{~m}^{2}$.

O solo pertence à unidade de mapeamento Santa Maria (Alissolo Hipocrômico argilúvico típico) e foi preparado de maneira convencional. A adubação foi realizada no sulco da semeadura, de acordo com a interpretação da análise química do solo. A adubação nitrogenada em cobertura foi parcelada em duas aplicações de $40 \mathrm{~kg} \mathrm{ha}^{-1}$ de nitrogênio nos estádios vegetativos de primeira e terceira folhas trifolioladas, V3 e V4, respectivamente. Os tratos culturais, como controle de insetos e de plantas invasoras, foram realizados sempre que necessário, de maneira que a cultura não sofresse competição (CEPEF, 2003).

A colheita e a trilha das plantas foram realizadas manualmente e, após a retirada das impurezas, os grãos foram secados ao sol e em estufa $\left(65\right.$ a $\left.70^{\circ} \mathrm{C}\right)$, até atingirem umidade média de $13 \%$, quando se 
determinou o rendimento de grãos e a coloração do tegumento dos grãos. Amostras de $100 \mathrm{~g}$ de grãos foram colocadas em placas de petri de $22 \mathrm{~cm}$ de diâmetro e $3 \mathrm{~cm}$ de altura, de maneira que os grãos cobriram completamente o fundo do recipiente. Um colorímetro, marca Minolta, modelo CR-310, foi utilizado para a leitura da claridade dos grãos, valor de "L".

Logo após, as amostras de grãos de cada cultivar foram moídas em micromoinho até a obtenção de partículas inferiores a $1 \mathrm{~mm}$, armazenadas em potes plásticos, devidamente identificados, e conservadas sob refrigeração até o momento de realização das análises de fibra. A fibra alimentar foi quantificada em amostras de grãos coletadas em 2005/06, em duplicata. As análises foram realizadas no Núcleo Integrado de Desenvolvimento em Análises Laboratoriais (NIDAL), do Departamento de Tecnologia e Ciência dos Alimentos da UFSM. A metodologia utilizada foi a descrita pela AOAC (1995), que determina analiticamente os teores de fibra alimentar total e insolúvel e quantifica, por diferença, o teor de fibra solúvel da amostra.

Os dados obtidos foram submetidos à análise de variância conjunta, sendo que o efeito de cultivar foi considerado fixo, e os efeitos de anos e de bloco, aleatórios. A eficiência do delineamento látice em relação ao blocos ao acaso foi determinada, pois quando esse valor é menor que a unidade, recomendase que a análise de variância do látice seja desprezada e que o conjunto de dados seja analisado como blocos ao acaso (RAMALHO et al., 2000). As análises estatísticas foram procedidas com o auxílio do programa GENES (CRUZ, 2001) e do aplicativo Office Excel.

\section{RESULTADOS E DISCUSSÃO}

Os valores do índice de eficiência relativa foram menores do que a unidade, por isso a análise da variância do látice foi desprezada, pois esse delineamento apresentou baixa eficiência, e o experimento foi considerado como blocos casualizados, como recomendado por RAMALHO et al. (2000).

Interação cultivar x ano foi observada em relação ao rendimento de grãos, à coloração do tegumento dos grãos e ao ciclo, evidenciando resposta diferenciada das cultivares crioulas aos anos de avaliação (Tabela 2).

$\mathrm{O}$ índice $\mathrm{B}$, que corresponde à relação entre o coeficiente de variação da variabilidade genética e o coeficiente de variação ambiental, indica que a variabilidade genética entre as cultivares estudadas é maior para a coloração do tegumento dos grãos do que a observada para rendimento de grãos e para ciclo. Sendo assim, a coloração do tegumento dos grãos, medida pela claridade da amostra (valor de "L"), foi eficiente para a diferenciação das cultivares crioulas de feijão, à semelhança do que foi observado por RIBEIRO et al. (2004) para cultivares desenvolvidas pela pesquisa.

As cultivares crioulas - "21 INT-ps 1", "9 BR-ps 5”, “9 BR-ps 15”, “9 BR-ps 13”, “9 BR-ps 7”, “38 MO M-ps 11” e “36 BR MP-ps 14” - são promissoras, pois apresentaram rendimento de grãos nos dois anos de avaliação similares estatisticamente aos da cultivar "BRS Campeiro" - desenvolvida pela pesquisa (Tabela 2). Essas cultivares poderiam ser avaliadas em ensaio de Valor de Cultivo e Uso (VCU) para a inscrição no Serviço Nacional de Proteção de Cultivares, no Ministério da Agricultura Pecuária e Abastecimento (SNPC-MAPA), de acordo com as regras estabelecidas em BRASIL (2006).

As cultivares crioulas "24 OP-ps 5”, "21 INTps 5” e “24 OP-ps 1” foram sempre de inferior rendimento de grãos, expressando baixo potencial de uso agrícola. Entretanto, recomenda-se a conservação de uma amostra de sementes para preservar a variabilidade genética e para investigar outros caracteres de importância agronômica.

Com relação à coloração do tegumento dos grãos, avaliaram-se cultivares de diferentes grupos comerciais. No grupo de cor, utilizaram-se duas cultivares testemunhas ("Iraí" e "Iapar 31"). As cultivares crioulas “38 MO M-ps 11”, “38 MO M-ps 13” e “38 MO M-ps 4” são de grãos do tipo mouro (valor de L entre 36 e 38), enquanto que "43 AM M-ps 13” e “43 AM M-ps 4” apresentaram grãos roxos (L compreendido de 26 a 29).

As demais cultivares avaliadas são do grupo comercial preto, sendo que a grande maioria apresentou valores de claridade (L) que satisfazem o padrão de preferência para o consumo, que nesse grupo compreende valores de L de 20 a 22 (RIBEIRO et al., 2003), à semelhança dos obtidos pelas testemunhas "BRS Campeiro" e "BRS Expedito". No entanto, as cultivares crioulas “25 BR M-ps 12”, “5 OP M-ps 9”, “23 BR-ps 6” e “19 OP-ps 8” - no ano agrícola de 2004/ 05 apresentaram os maiores valores de claridade dos grãos, o que pode restringir seriamente a comercialização dessas cultivares. Isso porque valores altos de L para feijão preto (superiores a 24) indicam grande presença de grãos arroxeados, o que é associado a grãos de qualidade inferior, que requerem maior tempo para o cozimento e, por isso, são de baixo valor comercial. Sendo assim, é importante a avaliação da coloração do tegumento dos grãos pelos programas 
Tabela 2 - Rendimento de grãos (rendimento, $\mathrm{kg} \mathrm{ha}^{-1}$ ), coloração do tegumento dos grãos (cor, L) e número de dias da emergência a maturação fisiológica (ciclo, dias) de cultivares crioulas de feijão avaliadas em dois anos agrícolas.

\begin{tabular}{|c|c|c|c|c|c|c|c|c|c|}
\hline \multirow{2}{*}{ Cultivar } & \multicolumn{3}{|c|}{-------Rendimento------- } & \multicolumn{3}{|c|}{-----------Cor----------- } & \multicolumn{3}{|c|}{----------Ciclo---------- } \\
\hline & $2004 / 05$ & $2005 / 06$ & Média & $2004 / 05$ & $2005 / 06$ & Média & $2004 / 05$ & $2005 / 06$ & Média \\
\hline "BRS Campeiro" $(\mathrm{P})^{2}$ & $2854 \mathrm{a}^{1}$ & $2002 \mathrm{a}$ & 2428 & $22,5 \mathrm{~h}$ & $21,4 \mathrm{~h}$ & 21,9 & $67,3 \mathrm{c}$ & $75,0 \mathrm{c}$ & 71,2 \\
\hline “6 OP M - ps 15” & 2626 a & 1191 c & 1908 & $20,8 \mathrm{j}$ & $22,5 \mathrm{f}$ & 21,6 & 69,7 c & 80,7 a & 75,2 \\
\hline “21 INT - ps 1" & $2484 \mathrm{a}$ & 1795 a & 2139 & $23,4 \mathrm{~g}$ & $21,8 \mathrm{~g}$ & 22,6 & $67,7 \mathrm{c}$ & $76,7 \mathrm{~b}$ & 72,2 \\
\hline “9 BR - ps 5” & $2480 \mathrm{a}$ & 2999 a & 2739 & $22,4 \mathrm{~h}$ & $21,2 \mathrm{~h}$ & 21,8 & $64,7 \mathrm{~d}$ & $74,0 \mathrm{c}$ & 69,3 \\
\hline “BRS Expedito (P)” & $2434 \mathrm{a}$ & $1386 \mathrm{~b}$ & 1910 & $21,6 \mathrm{i}$ & $21,9 \mathrm{~g}$ & 21,8 & $70,7 \mathrm{~b}$ & 79,0 a & 74,8 \\
\hline “9 BR - ps 15” & 2413 a & 1943 a & 2178 & $21,6 \mathrm{i}$ & $22,2 \mathrm{~g}$ & 21,9 & $63,3 \mathrm{~d}$ & $72,0 \mathrm{~d}$ & 67,7 \\
\hline “25 BR M - ps 12” & 2413 a & 1297 b & 1855 & $24,4 \mathrm{f}$ & $23,0 \mathrm{f}$ & 23,7 & 67,7 c & 78,3 a & 73,0 \\
\hline “16 OP MP - ps 8” & $2312 \mathrm{a}$ & $1325 \mathrm{~b}$ & 1818 & $21,9 \mathrm{i}$ & $22,5 \mathrm{f}$ & 22,2 & $70,7 \mathrm{~b}$ & 79,0 a & 74,8 \\
\hline “9 BR - ps 13” & $2266 \mathrm{a}$ & 2146 a & 2206 & $20,6 \mathrm{j}$ & $22,4 \mathrm{f}$ & 21,5 & $63,3 \mathrm{~d}$ & $71,7 \mathrm{~d}$ & 67,5 \\
\hline “5 OP M - ps 2” & $2242 \mathrm{a}$ & $1712 \mathrm{~b}$ & 1977 & $22,5 \mathrm{~h}$ & $21,6 \mathrm{~g}$ & 22,1 & $69,0 \mathrm{c}$ & $76,0 \mathrm{~b}$ & 72,5 \\
\hline “36 BR MP - ps 7” & 2226 a & $1644 \mathrm{~b}$ & 1935 & $21,5 \mathrm{i}$ & $22,7 \mathrm{f}$ & 22,1 & $64,0 \mathrm{~d}$ & $76,7 \mathrm{~b}$ & 70,3 \\
\hline “9 BR - ps 7” & $2210 \mathrm{a}$ & 1894 a & 2052 & $21,5 \mathrm{i}$ & $22,1 \mathrm{~g}$ & 21,8 & 62,5 e & $70,7 \mathrm{~d}$ & 66,5 \\
\hline “38 MO M - ps 11” & $2184 \mathrm{a}$ & 1816 a & 2000 & $38,1 \mathrm{c}$ & $37,1 \mathrm{~b}$ & 37,6 & $65,0 \mathrm{~d}$ & $74,0 \mathrm{c}$ & 69,5 \\
\hline “36 BR MP - ps 14” & 2165 a & 2260 a & 2212 & $20,7 \mathrm{j}$ & $22,2 \mathrm{~g}$ & 21,5 & 61,7 e & $70,7 \mathrm{~d}$ & 66,2 \\
\hline “34 OP - ps 14” & $2154 \mathrm{a}$ & $771 \mathrm{c}$ & 1462 & $21,0 \mathrm{j}$ & $21,9 \mathrm{~g}$ & 21,5 & $69,0 \mathrm{c}$ & 79,0 a & 74,0 \\
\hline “43 AM M - ps 13” & $2148 \mathrm{a}$ & $946 \mathrm{c}$ & 1547 & $29,2 \mathrm{~d}$ & 26,8 e & 28,0 & $69,0 \mathrm{c}$ & 78,7 a & 73,8 \\
\hline “9 BR - ps 9" & 2126 a & $924 \mathrm{c}$ & 1525 & $21,4 \mathrm{i}$ & $22,6 \mathrm{f}$ & 22,0 & 61,7 e & 79,0 a & 70,3 \\
\hline “36 BR MP - ps 12” & $2030 \mathrm{~b}$ & 1859 a & 1944 & $22,2 \mathrm{~h}$ & $21,8 \mathrm{~g}$ & 22,0 & 61,3 e & $72,0 \mathrm{~d}$ & 66,7 \\
\hline “36 BR MP - ps 13” & $2021 \mathrm{~b}$ & 1825 a & 1923 & $22,5 \mathrm{~h}$ & $20,1 \mathrm{i}$ & 21,3 & 61,3 e & $71,3 \mathrm{~d}$ & 66,3 \\
\hline “36 BR MP - ps 8” & 2014 b & $1973 \mathrm{a}$ & 1993 & $20,4 \mathrm{j}$ & $21,8 \mathrm{~g}$ & 21,1 & 61,3 e & $72,7 \mathrm{~d}$ & 67,0 \\
\hline "Iraí (C)” & 2011 b & 1577 b & 1794 & $60,6 \mathrm{a}$ & 50,4 a & 55,5 & $63,3 \mathrm{~d}$ & $75,0 \mathrm{c}$ & 69,2 \\
\hline “25 BR M - ps 8” & 2006 b & $1405 \mathrm{~b}$ & 1705 & $21,8 \mathrm{i}$ & $22,0 \mathrm{~g}$ & 21,9 & 67,7 c & 77,3 b & 72,5 \\
\hline "Iapar 31 (C)” & 2004 b & 1842 a & 1923 & 56,2 b & 50,6 a & 53,4 & 70,0 c & 75,7 b & 72,8 \\
\hline “5 OP M - ps 9” & 1976 b & $1545 \mathrm{~b}$ & 1760 & $24,1 \mathrm{f}$ & $22,5 \mathrm{f}$ & 23,3 & 67,0 c & 74,3 с & 70,7 \\
\hline “23 BR - ps 6” & $1956 \mathrm{~b}$ & $530 \mathrm{~d}$ & 1243 & 25,5 e & $20,5 \mathrm{i}$ & 23,0 & $71,3 \mathrm{~b}$ & 80,7 a & 76,0 \\
\hline “16 OP MP - ps 6” & $1943 \mathrm{~b}$ & $2222 \mathrm{a}$ & 2082 & $21,9 \mathrm{i}$ & $21,3 \mathrm{~h}$ & 21,6 & $70,7 \mathrm{~b}$ & $71,0 \mathrm{~d}$ & 70,8 \\
\hline “19 OP - ps 8” & $1909 \mathrm{~b}$ & $1651 \mathrm{~b}$ & 1780 & $23,8 \mathrm{f}$ & $20,0 \mathrm{i}$ & 21,9 & 68,3 c & $75,0 \mathrm{c}$ & 71,7 \\
\hline “38 MO M - ps 13” & $1821 \mathrm{~b}$ & 1697 b & 1759 & 37,2 c & $36,6 \mathrm{c}$ & 37,2 & $63,3 \mathrm{~d}$ & $72,0 \mathrm{~d}$ & 67,7 \\
\hline “43 AM M - ps 4” & $1783 \mathrm{~b}$ & $906 \mathrm{c}$ & 1344 & $28,9 \mathrm{~d}$ & $28,2 \mathrm{~d}$ & 28,6 & 69,0 c & 78,3 a & 73,7 \\
\hline “38 MO M - ps 4” & $1759 \mathrm{~b}$ & $1526 \mathrm{~b}$ & 1642 & 37,4 c & $36,3 \mathrm{c}$ & 36,8 & $63,3 \mathrm{~d}$ & $72,0 \mathrm{~d}$ & 67,7 \\
\hline "23 OP M - ps 2" & $1695 \mathrm{~b}$ & 1057 c & 1376 & $21,7 \mathrm{i}$ & $22,0 \mathrm{~g}$ & 21,9 & 68,0 c & 78,0 a & 73,0 \\
\hline “26 OP M - ps 11” & $1648 \mathrm{~b}$ & $841 \mathrm{c}$ & 1244 & $22,2 \mathrm{~h}$ & $22,7 \mathrm{f}$ & 22,5 & 70,0 c & $77,0 \mathrm{~b}$ & 73,5 \\
\hline “30 OP M - ps 11” & $1605 \mathrm{~b}$ & $1374 \mathrm{~b}$ & 1489 & $20,9 \mathrm{j}$ & $21,0 \mathrm{~h}$ & 21,0 & $70,7 \mathrm{~b}$ & 79,7 a & 75,2 \\
\hline “24 OP - ps 5” & 1147 c & $550 \mathrm{~d}$ & 848 & $23,1 \mathrm{~g}$ & $21,6 \mathrm{~g}$ & 22,4 & 73,3 a & 79,0 a & 76,2 \\
\hline “21 INT - ps 5” & $947 \mathrm{c}$ & $542 \mathrm{~d}$ & 744 & $23,1 \mathrm{~g}$ & $22,1 \mathrm{~g}$ & 22,6 & $74,0 \mathrm{a}$ & 77,7 b & 75,8 \\
\hline “24 OP - ps 1” & $534 \mathrm{~d}$ & $264 \mathrm{~d}$ & 399 & $23,2 \mathrm{~g}$ & $21,0 \mathrm{~h}$ & 22,1 & 74,3 a & 79,3 a & 76,8 \\
\hline Média & 2015 & 1459 & 1737 & 25,9 & 25,0 & 25,4 & 67,1 & 75,8 & 71,4 \\
\hline CVe (\%) & 16,93 & 19,73 & 18,17 & 1,39 & 1,50 & 1,45 & 2,23 & 1,92 & 2,07 \\
\hline CVg (\%) & 20,03 & 35,28 & 22,15 & 35,76 & 30,49 & 32,69 & 5,61 & 4,03 & 4,11 \\
\hline Índice B (CVg/Cve) & 1,18 & 1,79 & 1,22 & 25,70 & 20,31 & 22,62 & 2,51 & 2,10 & 1,99 \\
\hline
\end{tabular}

${ }^{1}$ Médias de tratamentos seguidas de letras diferentes na coluna diferem entre si a 5\% de probabilidade de erro pelo teste de Scott-Knott. CVe $(\%)$ = coeficiente de variação ambiental. CVg (\%) = coeficiente de variação da variabilidade genética. Índice B = relação CVg/CVe.

${ }^{2}$ Letras seguindo a identificação do genótipo representam: (P): cultivar testemunha de grãos pretos; (C): cultivar testemunha de grãos de cor.

de melhoramento, pois a aceitação para o consumo de determinada cultivar e o maior valor agregado do produto feijão é dependente do padrão de cor.

O número médio de dias da emergência à maturação fisiológica foi de 67,1 dias (2004/05) e de 75,8 dias (2005/06) (Tabela 2). De maneira geral, constatou-se que as cultivares foram mais precoces no primeiro ano agrícola, provavelmente pelo fato de ter ocorrido deficiência hídrica durante o subperíodo da floração plena à maturação fisiológica.

A utilização de cultivares de ciclo precoce é alternativa para os produtores rurais que realizam rotação ou sucessão de culturas e que necessitam obter o produto em menor tempo. Nesse sentido, foi possível 
observar que várias cultivares crioulas apresentaram ciclo precoce, à semelhança da cultivar "Iraí", constituindo excelente fonte de germoplasma para a obtenção de precocidade em feijão. As demais cultivares foram de ciclo intermediário, ou seja, há variabilidade genética para atender à demanda por cultivares de ciclos diferenciados.

A fibra alimentar variou de 21,96 (38 MO M-ps 13) a 31,75\% (24 OP-ps 1) (Tabela 3). Valores semelhantes foram obtidos em grãos de cultivares comerciais avaliados em dois municípios do Estado do Rio Grande do Sul (LONDERO et al., 2006b). Entretanto, valores superiores - de 33,39 a 39,39\% - foram verificados por LONDERO et al. (2005) e por LONDERO et al. (2006a) em cultivares comerciais e em linhagens segregantes de feijão. Considerando-se que o teor de fibra alimentar em feijão varia com o genótipo e que apresenta efeito da interação genótipo x ambiente, isso explicaria as variações observadas em diferentes ambientes (LONDERO et al., 2006b).

As cultivares crioulas apresentaram valores de fibra alimentar semelhantes as das cultivares desenvolvidas pela pesquisa - "BRS Campeiro", "BRS Expedito”, "Iraí” e “Iapar 31”. Cabe, no entanto, destacar as cultivares com valores de fibra alimentar superiores a 26\% - “24 OP-ps 1”, “25 BR M-ps 12”, “43 AM M-ps 4”, “9 BR-ps 5”, “5 OP M-ps 2”, “36 BR MP-ps 14”, “38 MO M-ps 4”, “24 OP-ps 5” e “26 OP M-ps 11” - pois são promissoras para uso em programas de hibridação controlada para o desenvolvimento de germoplasma com maior teor de fibra alimentar.

As cultivares crioulas com valores superiores a 23\% de fibra insolúvel foram: "24 OP-ps1”, “9 BR-ps 5”, “5 OPM-ps 2”, “24 OP-ps 5” e “25 BR Mps 8”. O consumo de grãos dessas cultivares poderia auxiliar na prevenção de doenças do trato gastrointestinal, pois a maior ingestão de fibra insolúvel acelera o tempo de trânsito intestinal (OLSON et al., 1987; MOORE et al., 1998; VANDERHOOF, 1998). Esses autores também destacam que as fibras solúveis têm a propriedade de diminuir a absorção de glicose e do colesterol plasmático. A utilização de cultivares de feijão com elevada fibra solúvel poderia propiciar efeitos preventivos ou terapêuticos em parcela considerável da população. Nesse sentido, destacam-se as cultivares com valores superiores a $6 \%$ de fibra solúvel “- 24 OP-ps 1”, “43 AM M-ps4”, “38 MO M-ps 4”, “38 MO M-ps 11”, “9 BR-ps 15”, “19 OP-ps 8” e “43 AM M-ps 13”. No entanto, estudos mais aprofundados são necessários para comprovar ou não os benefícios para a saúde do consumo dessas cultivares de feijão.

A cultivar crioula "24 OP-ps 1" obteve o maior teor de fibra alimentar (31,75\%) e o seu potencial de uso como alimento funcional deve ser investigado, pois apresenta também altas fibras insolúveis (23,93\%) e solúveis (7,82\%), apesar do menor rendimento de grãos obtido (Tabela 2).

Tabela 3 - Fibra insolúvel, fibra solúvel e fibra alimentar, em \%, de cultivares crioulas de feijão avaliadas em dois anos agrícolas.

\begin{tabular}{|c|c|c|c|}
\hline Cultivares & $\begin{array}{c}\text { Fibra } \\
\text { insolúvel }\end{array}$ & $\begin{array}{l}\text { Fibra } \\
\text { solúvel }\end{array}$ & $\begin{array}{c}\text { Fibra } \\
\text { alimentar }\end{array}$ \\
\hline & & $\%$ & \\
\hline “24 OP - ps 1” & 23,93 & 7,82 & 31,75 \\
\hline “25 BR M - ps 12” & 22,52 & 5,39 & 27,91 \\
\hline “43 AM M - ps 4” & 20,67 & 6,95 & 27,62 \\
\hline “9 BR - ps 5” & 24,91 & 2,18 & 27,09 \\
\hline “5 OP M - ps 2” & 26,82 & 0,24 & 27,05 \\
\hline “36 BR MP - ps14” & 22,72 & 4,10 & 26,82 \\
\hline “38 MO M - ps 4” & 20,22 & 6,39 & 26,61 \\
\hline “24 OP - ps 5” & 23,79 & 2,69 & 26,48 \\
\hline “26 OP M - ps 11” & 21,52 & 4,50 & 26,02 \\
\hline “16 OP MP - ps 8” & 21,68 & 4,20 & 25,87 \\
\hline “23 BR - ps 6” & 22,58 & 3,18 & 25,76 \\
\hline “36 BR MP - ps 12” & 20,49 & 5,21 & 25,70 \\
\hline “36 BR MP - ps 13” & 21,07 & 4,45 & 25,52 \\
\hline “30 OP M - ps 11” & 21,96 & 3,48 & 25,44 \\
\hline “34 OP - ps 14” & 20,91 & 4,48 & 25,39 \\
\hline “38 MO M - ps 11” & 18,93 & 6,44 & 25,37 \\
\hline "BRS Campeiro $(\mathrm{P})^{*}$ ” & 20,72 & 4,46 & 25,19 \\
\hline “9 BR - ps 15” & 19,02 & 6,00 & 25,02 \\
\hline "BRS Expedito (P)" & 20,29 & 4,53 & 24,82 \\
\hline “9 BR - ps 9” & 19,70 & 5,05 & 24,76 \\
\hline “25 BR M - ps 8” & 23,09 & 1,63 & 24,72 \\
\hline “21 INT - ps 5” & 18,83 & 5,73 & 24,55 \\
\hline “16 OP MP - ps 6” & 19,08 & 5,45 & 24,53 \\
\hline "Iapar 31 (C)" & 21,49 & 3,05 & 24,54 \\
\hline “Iraí (C)” & 20,00 & 4,49 & 24,49 \\
\hline “36 BR MP - ps 7” & 21,21 & 3,20 & 24,41 \\
\hline “9 BR - ps 7” & 20,87 & 3,52 & 24,39 \\
\hline “21 INT - ps 1” & 21,20 & 3,15 & 24,35 \\
\hline “5 OP M - ps 9” & 21,21 & 2,98 & 24,19 \\
\hline “19 OP - ps 8” & 17,56 & 6,39 & 23,95 \\
\hline “43 AM M - ps 13” & 17,14 & 6,23 & 23,37 \\
\hline “36 BR MP - ps 8” & 19,39 & 3,96 & 23,36 \\
\hline “9 BR - ps 13” & 19,73 & 3,27 & 23,00 \\
\hline “6 OP M - ps 15” & 19,91 & 2,60 & 22,51 \\
\hline “23 OP M - ps 2” & 18,84 & 3,39 & 22,24 \\
\hline “38 MO M - ps 13” & 19,09 & 2,87 & 21,96 \\
\hline Média & 20,92 & 4,28 & 25,19 \\
\hline
\end{tabular}

*Letras seguindo a identificação do genótipo representam: (P): cultivar testemunha de grãos pretos, (C): cultivar testemunha de grãos de cor.

Ciência Rural, v.38, n.3, mai-jun, 2008. 


\section{CONCLUSÕES}

As cultivares crioulas de feijão - "21 INT-ps 1”, “9 BR-ps 5”, “9BR-ps 15”, “9 BR-ps 13”, “9BR-ps 7”, “38 MO M-ps 11” e “36 BR MP-ps 14” - são promissoras para uso em programas de melhoramento genético por apresentarem alto potencial de rendimento de grãos e caracteres agronômicos desejáveis. A cultivar crioula "24 OP-ps 1" obteve o maior teor de fibra alimentar e o seu potencial de uso como alimento funcional deve ser investigado.

\section{AGRADECIMENTOS}

À Embrapa, pelo financiamento deste projeto, e ao professor Dr. Alberto Cargnelutti Filho, pelo auxílio na realização das análises estatísticas. Ao Conselho Nacional de Desenvolvimento Científico e Tecnológico (CNPq), pela concessão de bolsas à pesquisadora Nerinéia Dalfollo Ribeiro e à aluna Simone Saydelles da Rosa. À Fundação de Amparo à Pesquisa do Estado do Rio Grande do Sul (FAPERGS) e ao Fundo de Incentivo a Pesquisa (FIPE) da UFSM, pela concessão das bolsas de iniciação científica.

\section{REFERÊNCIAS}

ANTUNES, I.F. et al. Formação do PGR-I, Pool Gênico Riograndense I de feijão, no CPATB/EMBRAPA. In: REUNIÃO TÉCNICA ANUAL DE FEIJÃO E OUTRAS LEGUMINOSAS DE GRÃOS ALIMENTÍCIOS, 24., 1991, Santa Rosa, RS. Anais... Santa Rosa: Ipagro, 1991. 213p. p.23-25.

ACEVEDO, E.; BRESSANI, R. Contenido de fibra dietetica y digestibilidad del nitrogeno en alimentos centroamericanos: Guatemala. Archivos Latinoamericanos de Nutricion, v.40, n.3, p.439-451, 1990 .

AOAC INTERNATIONAL (Gaithersburg, Estados Unidos). Official methods of analysis of AOAC International. 16.ed. Washington, 1995. 200p.

BRASIL. Ministério da Agricultura, Pecuária e Abastecimento. Anexo IV. Requisitos mínimos para determinação do valor de cultivo e uso de feijão (Phaseolus vulgaris), para a inscrição no registro nacional de cultivares - RCN. 2006. Capturado em 21 ago. 2006. Online. Disponível na Internet: http://www.agricultura.gov.br.

CEPEF. Indicações técnicas para a cultura do feijão no Rio Grande do Sul 2003/04. Passo Fundo: UPF, 2003. 149p.
CRUZ, C.D. Programa GENES: versão Windows, aplicativo computacional em genética e estatística. Viçosa: UFV, 2001. 648p.

GEIL, P.B.; ANDERSON, J.W. Nutrition and health implications of dry beans: a review. Journal of the American College of Nutrition, v.13, n.6, p.549-558, 1994.

GUERRA, N.B. et al. Modificações do método gravimétrico não enzimático para determinar fibra alimentar solúvel e insolúvel em frutos. Revista de Nutrição, v.17, n.1, p.45-52, 2004.

HUGHES, J.S. Potential contribution of dry bean dietary fiber to health. Food Technology, v.45, n.9, p.122-126, 1991.

LONDERO, P.M.G. et al. Genetic variability for dietary fiber content in common bean populations. Crop Breeding and Applied Biotechnology, v.5, n.1, p.86-90, 2005.

LONDERO, P.M.G. et al. Herança dos teores de fibra alimentar e rendimento de grãos em populações de feijoeiro. Pesquisa Agropecuária Brasileira, v.41, n.1, p.51-58, 2006a.

LONDERO, P.M.G. et al. Variabilidade genética de cultivares de feijão para fibra alimentar. In: REUNIÃO SUL BRASILEIRA DE FEIJÃO, 8., 2006, Londrina, PR. Anais... Londrina: Iapar, 2006b. 226p. p.96-98.

McCLEAN, P.E. et al. Coefficient of parentage and cluster analysis of north American dry bean cultivars. Crop Science, v.33, n.1, p.190-193, 1993.

MOORE, M.A. et al. Soluble and insoluble fiber influences on cancer development. Critical reviews in Oncology/ Hematology, v.27, n.3, p.229-242, 1998.

OLSON, A. et al. Chemistry and analysis of soluble dietary fiber. Food Technology, v.4, n.2, p.71-82, 1987.

RAMALHO, M.A.P. et al. Experimentação em genética e melhoramento de plantas. Lavras: UFLA, 2000. 326 p.

RIBEIRO, N.D. et al. Progresso genético em caracteres agronômicos no melhoramento do feijoeiro. Ciência Rural, v.33, n.4, p.629-633, 2003.

RIBEIRO, N.D. et al. Efeitos da interação genótipo x ambiente no ciclo e na coloração do tegumento dos grãos do feijoeiro comum. Bragantia, v.63, n.3, p.373-380, 2004.

VANDERHOOF, J.A. Immunonutrition: the role of carbohydrates. Nutrition, v.14, n.7/8, p.595-598, 1998. 